\title{
Secondary hypogonadism following hand, foot, and mouth disease in an adult: a case report and review of literature
}

\author{
Zhaoying Chen ${ }^{1}$, Chen Jiang ${ }^{2}$, Xiaoyu Cheng ${ }^{1}$, Lidan Ma', Ying Xin ${ }^{1}$, Tian Liu ${ }^{1}$ and Ruixia Sun ${ }^{1 *}$ (1)
}

\begin{abstract}
Background: Previous reports have described hypogonadism associated with virus infection such as hantavirus, human immunodeficiency virus (HIV) or severe acute respiratory syndrome coronavirus 2 (SARS-COV-2). However, to our best knowledge there has been no case report of secondary hypogonadism following hand, foot, and mouth disease (HFMD).

Case presentation: A previously healthy 28-year-old man with no history of major physical and psychological trauma, presented with bilateral gynecomastia and erectile dysfunction 2 weeks after HFMD. Laboratory testament showed the level of gonadotropin hormones declined. Imaging examination demonstrated no major abnormal change in pituitary or reproductive system. The diagnosis of hypogonadism was established. Then the patient was ordered to maintain mental health outward of hospital without drug intervention. One month after presentation, his gonadotropin hormone level and sexual desire had recovered, while bilateral gynecomastia and erectile dysfunction symptoms disappeared.
\end{abstract}

Conclusions: Physicians should notice the possibility for hypogonadism in adult patients with a recent history of HFMD.

Keywords: Hand-foot-mouth disease, Hypogonadism, Adult-onset, Case report

\section{Background}

Hand, foot, and mouth disease (HFMD) is a common disease caused by different types of viruses [1]. Most serotypes of enterovirus A group, such as coxsackievirus (CV) A2, A4, A5, A8, A10, A16 and enterovirus type 71 (EV71), and some serotypes of enterovirus B group, such as CVB2, B4, and few echovirus (ECV) are related to its pathogenesis [2]. Adult HFMD may be caused by more virulent viruses, particularly CVA6. Usually, HFMD occurs in children under 5 years of age and present with a mild and self-limited syndrome [3, 4]. However, adults,

\footnotetext{
*Correspondence: 18678991617@163.com

1 Department of Endocrinology and Metabolism, The Affiliated Hospital

of Qingdao University, Qingdao 266003, China

Full list of author information is available at the end of the article
}

especially those living with infected children, may suffer from HFMD. Complications of HFMD involve nail shedding, pulmonary edema, myocardial impairment, purpura and neurological sequelae $[3,5,6]$. Hypogonadism following HFMD in sexual mature adult has not been reported before. Here, we present the first case report of secondary hypogonadism associated with HFMD.

\section{Case presentation}

A previously healthy 28 -year-old male presented with bilateral gynecomastia and erectile dysfunction for 1 month. The man with normal growth and development was sexually active before, denying history of major physical and psychological trauma. He also had no contact history with chemical, radioactive or toxic substances. The patient had seen a doctor at local 
hospital for the symptoms of fever, herpes on hands, feet as well as mouth and was diagnosed as HFMD. He recovered quickly after using ibuprofen and ribavirin for 2 days. 2 weeks after the diagnosis, the patient developed the symptoms of hyposexuality, erectile dysfunction with bilateral breast pain and development and clear nipple discharge. He came to our endocrinologist office, and the physical exam showed the patient had gynaecomastia at P2 according to the Tanner-Stage score system, and a ductile mass with a diameter of about $2 \mathrm{~cm}$ can be palpated under the nipple, which secreted clear discharge after squeezing. Testicular volume was evaluated about $15 \mathrm{ml}$, pubic hair P5, with penis length $12 \mathrm{~cm}$, circumference $9 \mathrm{~cm}$. His olfactory function was normal. Laboratory findings showed the level of gonadotropin and gonadal hormones declined. Luteinizing hormone (LH) level was $1.15 \mathrm{mIU} / \mathrm{ml}$ (normal range $1.70-8.60 \mathrm{mIU} / \mathrm{ml}$ ), follicle-stimulating hormone (FSH) level was $1.26 \mathrm{mIU} /$ $\mathrm{ml}$ (normal range $1.50-12.40 \mathrm{mIU} / \mathrm{ml}$ ), testosterone $(\mathrm{T})$ level was $3.19 \mathrm{nmol} / \mathrm{l}$ (normal range 9.90-27.80 mIU/ $\mathrm{ml}$ ), estradiol $\left(\mathrm{E}_{2}\right)$ level was below $18.35 \mathrm{pmol} / \mathrm{l}$ (normal range $99.40-192.00 \mathrm{mIU} / \mathrm{ml})$. Progesterone (P, normal range $<0.159-0.474 \mathrm{nmol} / \mathrm{l}$ ), insulin (INS, normal range $2.6-24.9 \mu \mathrm{IU} / \mathrm{ml})$, growth hormone $(\mathrm{GH}$, normal range 0.03-2.47 ng/ml), insulin-like growth factor-1 (IGF1 , normal range $60-350 \mathrm{ng} / \mathrm{ml}$ ), thyroid stimulating hormone (TSH, normal range $0.51-4.30 \mu \mathrm{IU} / \mathrm{ml}$ ), free triiodothyronine (T3, normal range $3.10-6.80 \mathrm{pmol} / \mathrm{l}$ ), free thyroxine (T4, normal range 12.6-21.0 pmol/l) were within normal range. In addition, the result of overnight low-dose dexamethasone suppression test was normal (Cortisol, COR $<50 \mathrm{nmol} / \mathrm{L}$ ). There was no evident abnormity index showing in carbohydrate antigen 19-9 (CA19-9), carbohydrate antigen 125 (CA125), carcino-embryonic antigen (CEA), alpha-fetoprotein (AFP) and human chorionic gonadotropin- $\beta$ (HCG$\beta)$ (Additional file 1: Table S1). Semen examination revealed lower sperm count, density and motility. The patient was subjected to a $\mathrm{GnRH}$ intramuscular injection (i.m.) infusion test (triptorelin, $100 \mu \mathrm{g}$ ). Our result (Additional file 1: Table S2) showed that peak LH level (more than 3 times compared to the baseline) after an i.m. infusion test of GnRH occurred at $60 \mathrm{~min}$, while FSH had no noticeable change. With respect to imaging examinations, breast ultrasound image demonstrated gland-like echo at both sides $(1.7 \times 1.5 \times 0.7 \mathrm{~cm}$ on the right side and $1.6 \times 1.6 \times 0.8 \mathrm{~cm}$ on the left side). The male reproductive system ultrasound showed calcification of prostate and cyst of right caput epididymidis. Plain chest computerized tomography (CT) showed multiple ground glass attenuation in both lungs and suspicious infectious lesions. Plain adrenal CT and
Dynamic enhanced magnetic resonance imaging (MRI) showed there were no obvious abnormal changes in pituitary or adrenal.

Following these conditions, the diagnosis of hypogonadism was established. Clinicians speculated that the disease was caused by HFMD-associated virus attacking hypothalamic neurons. The patient received no drug intervention and was ordered to keep a good mood outward of hospital. The function of hypothalamic-pituitary-gonadal axis (HPG axis) should be revalued after a 1-month observation period when medications are not recommended. The patient came back for a return visit after the 1-month follow-up. The recovery of gonadotropin hormone level was shown in Additional file 1: Table S3. Other laboratory findings were negative. Semen examination was normal. The patient reported morning erection, spermatorrhea, recovery of sexual desire and satisfying sex life of 4-5 times per week. Physical examination found that his bilateral breast mass and nipple discharge had disappeared.

\section{Discussion and conclusion}

To the best of our knowledge this is the first report of HFMD-related hypogonadism in an adult. HFMD is an infectious disease caused by Enteroviruses (EVs). Usually, HFMD affects children younger than 5 years old, however it can still affect adults [3, 7]. HFMD patients could present with neurological injury and complications, according to previous researches, the main neurological manifestations are myoclonic jerks, aseptic meningitis or encephalitis $[8,9]$. So, this patient's clinical course is quite unique for second hypogonadism in adult occurring following HFMD. Laboratory tests of the case showed evidently reduced levels of gonadotropins and sex hormones while other anterior pituitary hormones showed no deficiency, which suggested HFMD-induced damage of central nervous system could lead to hypothalamic and/or pituitary dysfunction.

Some previous reports have described secondary hypogonadism associated with HIV, hantavirus and SARS-CoV-2 virus infection [10-13], and several mechanisms of such severe complication were presented. For HIV infection, an observational cohort study (CHAMPS) conducted in New York found that among HIV-infected males, uncontrolled HIV viraemia $(910,000$ copies/ml) was significantly associated with secondary hypogonadism [14]. The cause of hypogonadism in HIV-infected men could be multi-factorial related to damage of either hypothalamic or pituitary areas by tumor or inflammation and specific drugs use such as exogenous androgen. For hantavirus infection, previous studies have found that hantavirus infection can cause $56 \%$ patients presenting with low serum 
gonadal hormone levels [11], the mechanism involved could be virus-induced central nervous system infection leading to transient or permanent hypothalamic and/or pituitary dysfunction [15]. There may also be immune factors, including excessive production of proinflammatory factors in acute phase of infection, leading to immune-mediated endothelial cell injury [16]. In the case of COVID-19, a previous research conducted on 81 male patients of COVID-19, which reported lower serum testosterone levels, higher LH levels [17]. Other studies implied SAR-CoV2 infection might lead to hypogonadism via multiple possible mechanisms such as testicular injury, oxidative stress and psychological stress [10, 18].

Secondary hypogonadism following HFMD may also share the mechanisms with hypogonadism caused by the other virus infection. In this case, the patient experienced complete pubertal development, thus congenital factors could be excluded. Psychological factors might not be the initial factor of sexual dysfunction since patient denied the history of psychological trauma and had no emotional discord with his sexual partner. Also, the patient had no history of consuming drugs acting on endocrine system and no evidence of the vascular abnormalities, peripheral neuropathy and testicular disease like orchitis was found. Besides, the result of GnRH stimulating test showed that the pituitary function was well-behaved and there was no pituitary adenoma, empty sella or other positive manifestations according to pituitary dynamic enhanced MRI. Therefore, the mechanism involved HFMD-associated hypogonadism seems to be that infection induce hypothalamic and/or pituitary dysfunction and suppress activity of hypothalamic-pituitary-testicular axis, causing reduced luteinizing hormone $(\mathrm{LH})$ and testosterone levels.

In summary, HFMD virus infection could be an etiologic factor of hypogonadism. Physicians should notice the possibility for hypogonadotropic hypogonadism in adult patients with a recent history of HFMD.

\section{Abbreviations}

HFMD: Hand, foot, and mouth disease; CT: Computed tomography; GnRH: Gonadotropin-releasing hormone.

\section{Supplementary Information}

The online version contains supplementary material available at https://doi. org/10.1186/s12879-022-07030-0.

Additional file 1: Table S1. Laboratory Examination Data on Admission. Table S2. Data of GnRH agonist stimulating test. Table S3. Endocrinological Examination Data after HFMD.

Acknowledgements

Not applicable.

\section{Authors' contributions}

$Z C, R S, X C, L M, Y X$ and TL performed patient follow-up, clinical diagnosis and treatment. ZC, CJ, RS finish the collection of data. ZC, CJ, RS draft the manuscript and $X C, L M, Y X, T L$ and RS were involved in editing of the manuscript. All authors read and approved the final manuscript.

Funding

None declared.

Availability of data and materials

All relevant data to this case are included within the article.

\section{Declarations}

Ethics approval and consent to participate

Not applicable.

\section{Consent for publication}

Written informed consent was obtained from the patient for publication of this case report.

\section{Competing interests}

The authors declare that they have no competing interests.

\section{Author details}

${ }^{1}$ Department of Endocrinology and Metabolism, The Affiliated Hospital of Qingdao University, Qingdao 266003, China. ${ }^{2}$ Department of Gastroenterology, The Affiliated Hospital of Qingdao University, Qingdao 266003, China.

Received: 18 June 2021 Accepted: 4 January 2022

Published online: 15 January 2022

\section{References}

1. Robinson CR, Doane FW, Rhodes AJ. Report of an outbreak of febrile illness with pharyngeal lesions and exanthem: Toronto, summer 1957; isolation of group A Coxsackie virus. Can Med Assoc J. 1958;79(8):615-21.

2. Ramirez-Fort MK, et al. Coxsackievirus A6 associated hand, foot and mouth disease in adults: clinical presentation and review of the literature. J Clin Virol. 2014:60(4):381-6.

3. Wang J, et al. Epidemiological characteristics of hand, foot, and mouth disease in Shandong, China, 2009-2016. Sci Rep. 2017;7(1):8900.

4. Koh WM, et al. Severity and burden of hand, foot and mouth disease in Asia: a modelling study. BMJ Glob Health. 2018;3(1):e000442.

5. Liu J, et al. Epidemic pattern of hand-foot-and-mouth disease in Xi'an, China from 2008 through 2015. BMC Infect Dis. 2019;19(1):19.

6. Esposito S, Principi N. Hand, foot and mouth disease: current knowledge on clinical manifestations, epidemiology, aetiology and prevention. Eur J Clin Microbiol Infect Dis. 2018;37(3):391-8.

7. Cox B, Levent F. Hand, foot, and mouth disease. JAMA. 2018;320(23):2492.

8. Yang $X$, et al. Clinical features and phylogenetic analysis of severe handfoot-and-mouth disease caused by Coxsackievirus A6. Infect Genet Evol. 2020;77:104054.

9. Lu HK, et al. Prognostic implications of myoclonic jerk in children with enterovirus infection. J Microbiol Immunol Infect. 2004;37(2):82-7.

10. Dutta S, Sengupta P. SARS-CoV-2 and male infertility: possible multifaceted pathology. Reprod Sci. 2021;28(1):23-6.

11. Makela S, et al. Hormonal deficiencies during and after Puumala hantavirus infection. Eur J Clin Microbiol Infect Dis. 2010;29(6):705-13.

12. Maffezzoni F, et al. Hypogonadism and bone health in men with HIV. Lancet HIV. 2020;7(11):e782-90.

13. Wong N, Levy M, Stephenson I. Hypogonadism in the HIV-infected man. Curr Treat Options Infect Dis. 2017:9(1):104-16.

14. Klein RS, et al. Androgen levels in older men who have or who are at risk of acquiring HIV infection. Clin Infect Dis. 2005;41(12):1794-803.

15. Schaefer $S$, et al. Hypothalamic-pituitary insufficiency following infectious diseases of the central nervous system. Eur J Endocrinol. 2008;158(1):3-9. 
16. Avsic-Zupanc T, Saksida A, Korva M. Hantavirus infections. Clin Microbiol Infect. 2019;21S:e6-16.

17. Pan $F$, et al. No evidence of severe acute respiratory syndrome-coronavirus 2 in semen of males recovering from coronavirus disease 2019. Fertil Steril. 2020;113(6):1135-9.

18. Delgado-Roche L, Mesta F. Oxidative stress as key player in severe acute respiratory syndrome coronavirus (SARS-CoV) infection. Arch Med Res. 2020;51(5):384-7.

\section{Publisher's Note}

Springer Nature remains neutral with regard to jurisdictional claims in published maps and institutional affiliations.

- fast, convenient online submission

- thorough peer review by experienced researchers in your field

- rapid publication on acceptance

- support for research data, including large and complex data types

- gold Open Access which fosters wider collaboration and increased citations

- maximum visibility for your research: over 100M website views per year

At BMC, research is always in progress.

Learn more biomedcentral.com/submissions 